of observation and experiment. The question at issue is in reality a very easy one to state. It is the old problem of the unity or diversity of the streptococci found in man. This is a question capable of experimental investigation. Dr. Gordon regards the streptococci as diverse, because different strains give different series of reactions in his test media. I differ from him as to whether this indisputable fact establishes his claim. The crux of the question is clearly whether the tests are constant or inconstant-i.e., whether the reactions of any given strain of streptococci in the test media are stable or unstable and liable to exhibit variations. I have repeatedly shown that the reactions are not stable at all, but highly variable.

Dr. Gordon's belief in the stability of the reactions was insecurely founded. It rested, as his original communications show, upon observations of the reactions of individual strains of streptococci "for periods up to a fortnight." Had he continued his examination of these organisms for a longer time, and been content to reach his conclusions somewhat less hastily, he might probably have modified this belief. After studying certain strains of streptococci continuously for more than four years I am in a position to state with confidence that Dr. Gordon is misled in regarding his tests as constant. They vary on continued cultivation of the streptococci, whether in artificial media or by passage through the bodies of animals. Accordingly these tests afford no evidence of the diversity of the streptococci pathogenetic for men.

So far from attempting to wreck the tests, my first step on arriving at conclusions in disagreement with his own was to inform Dr. Gordon by letter of the fact in June, 1910, and to invite him to be present at the reading of my first communication on the subject, in order that I might have the wenefit of his opinion and criticism. This proved to be impossible. But with a prescience which continues to fill me with wonder Dr. Gordon was able to complete and place a reply, of which he admits the material portion to have been a criticism of technique, more than three months (Dec. 12th, 1910-March 30th, 1911) before the publication of the paper in which my technique was made known, and when nothing had appeared beyond a few lines of preliminary statement (and two tables of results) containing no information of any kind regarding methods. This in itself was a remarkable achievement.

But what Dr. Gordon euphemistically speaks of as a criticism "largely on the ground of technique" was, in fact, a definite implication that I was not alive to the ordinary requirements of bacteriological method, and reached my conclusions by the observation of cultures which were alternatively either impure or dead, or by using impure materials in the tests. ${ }^{2}$ He now gathers, as he says, that Professor Beattie's work is "not above suspicion on the same grounds." Unless these remarks are merely frivolous or intended to be understood in a purely " Pickwickian sense," it must indeed be a distressing experience to Dr. Gordon to feel himself called upon thus to sit in judgment on the incapacity of Professor Beattie and myself.

But I venture to anticipate that his position will fail to command any general assent or confidence when it is seen that the only defence at present offered of the theory of the diversity of streptococci isolated from the human subject consists in the implied suggestion that those who differ from him in regard to this question do so because they are either incompetent to make pure cultures of streptococci, or so wareless as not even to ascertain whether their cultures are alive or dead.

In conclusion, I may perhaps be permitted to point out once again that the variations which occur in the test reactions of streptococci in Gordon's media are largely dependent on the character of the environment in which the organisms concerned have previously been growing. It follows that these reactions may in certain cases afford some evidence as to the source and origin (and therefore in some degree as to the probable virulence for the time being) of particular strains, and this in my opinion constitutes the only present value of Gordon's tests. - I am, Sir, yours faithfully,

$$
\text { E. W. AINLEY WALKER. }
$$

University College, Oxford, Nov. 18th, 1912.

To the Editor of THE LANCET.

SIR,- - I have noticed that in some cases of chronic rheumatism associated with bronchial catarrh and a habit

2 Journal of Pathology and Bacteriology, 1911, vol. xv., p. 323. of swallowing the sputum the rheumatism disappeared when that habit was checked. In one marked instance the sputum was teeming with streptococci. This would seem to lend support to Dr. M. H. Groraon's view as to the cause of rheumatism and to indicate that rheumatic patients should be questioned and cautioned about the disposal of their sputum.

Keswick, Nov, 16th, 1912. I am, Sir, yours faithfully, W. D. ANDERSON.

\section{TUBERCULOSIS AND VENTILATION.}

\section{To the Editor of THE LANCET.}

SIR, - On reading the provisions of the National Insurance Act as they refer more particularly to sanatoriums for the treatment of tuberculosis of lung, it has occurred to me that the maxim so often quoted, "Prevention is better than cure," should specially apply to this terrible disease, by which I mean that every effort that will diminish the incidence of tuberculosis should be insisted upon.

As regards the construction of dwelling-houses both in urban and rural districts, and especially the former, I believe I am correct in asserting that the efforts of sanitary authorities and the Local Government Board fall short of common. sense requirements, and that by failing to insist upon adequate ventilation-particularly in the crowded dwelling. houses of the poorer classes - those authorities are responsible for the incidence and spread of tubercle. This, of course, is a grave accusation to bring in this highly (?) civilised country of ours, but to the best of my belief and from the historical statistics afforded by the medical services of the navy and army, and from my own observation in various towns and rural districts of England, there is no doubt that there still exist such serious defects in the ventilation of dwelling-houses that the spread of tubercle is favoured thereby.

Looking back upon army statistics and the days when both at home and abroad men were crowded together in barracks insufficientiy ventilated, that great pioneer of sanitary science, Dr. Parkes, clearly showed the vital necessity of more cubic air space and better ventilation, and by wisely following his teaching and advice the naval and military authorities were able to reduce markedly the incidence, invaliding, and mortality from phthisis. In this connexion I recall a visit I once made to "Stony Hill," Jamaica, nearly 20 years ago. Formerly used as a military station for European troops and then as a reformatory for negro boys, the rooms still bore traces of the old days when European soldiers slept in bunks slung close together. I was told that yellow fever, phthisis, and other infectious diseases made terrible ravages among the troops. The same tale of overcrowding and deficient ventilation applied to all parts of the world where British troops were stationed, but, happily, through Parkes's teaching, great improvements were brought about, particularly with reference to tubercle or phthisis ; for by increasing the cubic air space and improving the ventilation of all barrack rooms the admissions to hospital for phthisis were soon reduced. I lay emphasis upon this recorded improvernent of the health of the army because it bears directly upon the question of proper ventilation of dwelling houses in civil life.

Now the sanitary authorities are apparently under the impression that as long as a living or sleeping room is provided with a fireplace, that is quite sufficient for the extraction of vitiated air. This is a very serious error. Supposing, for instance, six people are occupying a small room of a cottage, the air is warmed and fouled in the process of respiration and rises to the top of the room, where it cools and then descends, gaining fresh exhalations of $\mathrm{CO}_{2}$, and especially organic matter, until as time goes on the whole air of that rocm becomes foul and poisonous. What happens if one of the occupants is the subject of tubercle of lung and to those who are not already infected? If the foul air cannot escape by the fireplace and chimney it descends to the level of the occupants, who may inhale that poisonous air, and so we may have a spread of a notifiable disease.

In proof of the insufficiency of fireplaces as exits for vitiated air may be quoted many fatal cases of poisoning by coal-gas which have occurred from time to time. There were fire-places in the rooms, but the gas 'could not escape thereby. If the rooms had been provided with suitable exit ventilators at the ceiling level there would have been no fatalities to record, nor would gas explosions be so frequent. 
I have quoted the well-worn phrase, "Prevention is better than cure," because I desire to show how obviously the purity of the air of living and sleeping rooms is associated with the well-recognised benefit of the open-air treatment of tubercle of the lung in sanatoriums and in private, for by insisting upon the purity of the air of living and sleeping rooms much phthisis would be prevented, and the treatment of tubercle begun at the proper starting-point-namely, in the home.

What should be done, therefore, and insisted upon by all urban and rural sanitary authorities, is to have, above everything, proper exits, so placed that the warm and vitiated air can escape from the room; and the proper place for these exits is as near as possible to the ceiling and opening into the chimney flue. I am aware that this is all laid down in the books, but it is not insisted upon by sanitary authorities, and in this lies the mischief. There are, I know, noiseless exit ventilators which will not only allow foul air to escape by the chimney, but which prevent down draught and smoke from entering the room, and these can be placed in position for a few shillings per room-a mere tritle when the benefits they ensure are considered.

I would, in conclusion, emphasise how important it is for the health of people occupying small houses with a low cubic air space that the air should be as pure as possible. The aim should be, of course, to render the air of sleeping and living rooms as pure as that outside, and this can only be accomplished by changing the air of those rooms often enough. The vitiated air must be extracted or find an easy exit from rooms which are too often overcrowded and the cubic air space consequently reduced to an unhealthy or dangerous minimum. believe this can be done in the way indicated, but it will need to be enforced by the proper sanitary authorities. Architects, surveyors, and especially builders, will not trouble, as they seem to have an idea that proper exits for foul air are really superfluous or unnecessary in dwelling-houses. The responsibility must, therefore, remain with the sanitary anthorities and the Local Government Board of this country. Surely, then, at this time when a National Insurance Act is at work with the object of providing sanatoriums for the treatment of tuberculosis by fresh air, one of the most important factors in diminishing the incidence of this scourge at its source is efficient ventilation in the homes of the insured and which will check the spread of infection. This should be a compulsory charge of the authorities mentioned, otherwise we are only dealing in half and belated measures, which are never attended with the best results.

I am, Sir, yours faithfully,

J. D. ReChitT, M.D. Brux., M.R.C.S. Eng., L.S.A. Talgarth-road, West Kensington, Nor. 8th, 1912.

\section{CEREBRAL ANGIOSPASM. To the Editor of THE LANCET.}

SIR,-Having had the good fortune to graduate from Edinburgh in the "seventies," Dr. William Russell cannot be expected to have a very accurate knowledge of a textbook which did not appear until 1892; but having written so much and so well on arterio-sclerosis he might have read the section on the subject in some one of the eight editions before saying in THE LANCET of Nov. 16th (p. 1351): "How little this communication of Dr. Peabody influenced medical teaching or thinking is shown by the absence of any reference to this condition in Sir William Osler's excellent and popular book ...... down to the 1909 edition, at least, so far as I have been able to discover." My knowledge of transient aphasia and monoplegia in arterio-sclerosis dates from the early "eighties," when a dear friend and colleague had scores of attacks. Dr. Peabody's second paper was read while I was deep in the preparation of the first edition; and here is the paragraph on the subject--concise and clear enough for a student's manual. "Transient hemiplegia, monoplegia, or aphasia may occur in advanced arterio-sclerosis. Recovery may be perfect. It is difficult to say upon what these attacks depend. Spasm of the arteries has been suggested, but the condition of the smaller arteries is not very favourable to this view. Peabody has recently called attention to these cases, which are more common than indicated in the literature" (p. 669, first edition, 1892). In the second edition I added a note upon vertigo and slow pulse. Subsequent editions were unchanged until the present (eighth, 1912).

Oxford, Nov. 17th, 1912. I am, Sir, yours faithfully,

\section{THE "CONTINUOUS INHALATIONS" TREATMENT OF TUBERCULOSIS.}

\author{
To the Editor of THE LANCET.
}

Sir,-After the delivery of the Bradshaw lecture by Dr. David B. Lees, and after what Mr. S. N. Bruce has written on the same subject on page 1318 of THE LANCET of Nov. 9th, I think that some might be interested to hear my experience. I believe that I may almost claim to have introduced into practice "continuous inhalations" for the treatment of pulmonary tuberculosis.

The origin of the idea started from Lister's work. In the summer of 18781 spent some months in London at King's College Hospital in order to see the wonderful effects of the antiseptic treatment that Lister had introduced in his clinic at King's College. As when he was at Edinburgh, so too in London we were a lot of medical men from all parts of the world, anxious to know everything about the great reform, and to see how Spencer Wells performed his laparotomies at the Samaritan Hospital. When I came back to Padua, where I was assistant at the University, having occasion to see a good number of consumptive patients, it seemed to me that the worst symptoms (shivering, fever, great perspiration) were due to the same causes which were prevented by the antiseptic treatment. When tubercles have opened into the bronchi ulcerations are left in direct contact with the air, whose "germs" do infect, in the same manner that external wounds are infected. "The worst symptoms of consumption are then symptoms of septicæmia. Is it not possible to apply to the affected lungs the same antiseptic treatment that Lister has introduced for external wounds!" That was the question that I put then to myself and which I tried to solve.

In the winter of $1879 \mathrm{I}$ made an inhaler. It was an oral one ; the patient had to inspire the air which was forced to pass first through an antiseptic liquid, mainly composed of turpentine oil and carbolic acid. This inhaler gave me no good results, and I discarded it. It is the same that we still see sold everywhere, which is based on the same principle as the Junker inhaler for chloroform. A year later I tried a kind of cage made with fine wire net, at the bottom of which I put a sponge for receiving the antiseptic liquid. This cage was applied to mouth and nose and fastened at the back of the head in order to be worn continuously day and night.

The sweet voice of Lister, as sweet as he was in all his manners, used to insist on the fact that the antiseptic treatment must be continuous. The first results were a great improvement, and I tried more, and systematically since 1883, when I was a country doctor on the mountains of Bergamo, and described this kind of treatment by the name of "continuous inhalations."

In 1899 I wrote a book on the subject, "Cura e guarigione della tubercolosi polmonare" (Città di Castello, Tip. Lapi), and this book was translated into English and published in 1901 by John Wright and Co., Bristol ; but as the title of "Treatment and Cure of Pulmonary Tuberculosis" seemed too strong the English title is "Pulmonary Tuberculosis, its Prevention and Cure." In 1904 appeared here the second edition, still with the title "Cura e guarigione," and now I am preparing the third edition. This treatment of con tinuous inhalations is quite familiar here in Italy, and I think that at this moment while I am writing perhaps not less than 5000 patients are using it.

Now about the "cure." I am quite confident in asserting, after an experience of 30 years, during which $I$ have treated more than 2000 consumptives, and seen treated many and many more, that when the tuberculosis is simply bacillary the "cure" is certain. From this distinct stage of pure pulmonary tuberculosis, when the tubercles open into the bronchi we enter another very distinct stage, the stage of septicæmia. This begins with simple vlcerations infected by the common bacteria of the air, and goes on to the total destruction of the lungs with an enormous quantity of cavities of every description and dimension, full of a liquid 